\title{
Social reintegration service after fistula repair and its challenges in North Gondar, Ethiopia: Women's perspectives: A qualitative study
}

Debrework Tesgera Bashah ( $\square$ debre2012@gmail.com )

University of Gondar https://orcid.org/0000-0002-6631-1368

Abebaw Gebeyehu Worku

University of Gondar

Mezgebu Yitayal Mengistu

University of Gondar

Telake Azale

University of Gondar

Research article

Keywords: Challenges; Ethiopia; Obstetric fistula; Social reintegration; Women's perspectives.

Posted Date: November 27th, 2019

DOI: https://doi.org/10.21203/rs.2.17777/v1

License: (a) (i) This work is licensed under a Creative Commons Attribution 4.0 International License. Read Full License 


\section{Abstract}

Back ground: Following a fistula repair, there is a need to rehabilitate and reintegrate women into society. Existing interventions are not well documented or not sufficient to maintain victims' life and in most cases the issue of reintegration depends up on treatment success. Data on how reintegration has fulfilled women's needs is sparse. Therefore, the aim of this study was to explore the needs and challenges of women on post obstetric fistula repair. Method: A qualitative, phenomenological approach was used through in-depth interviews to explore women`s perspectives on reintegration service. Respondents were selected by purposive and snow ball sampling until data saturation was reached. Women were interviewed at least one year after they obtained surgical correction. Open code version 4.03 and thematic analysis was used to analyze the data. Result: Twelve women after fistula repair were interviewed at different settings; their median age at interview was 27 (range 24- 45). Five were fully continent and six claimed to have either stress or urge incontinence. Repair sessions ranged between 1-5surgeries with an average period of 6.25 years after treatment. The meaning attached to reintegration slightly differed between those women who regained continence and those with unsuccessful repair. Surgical correction, resource support and restoration of social health were found to be the most important aspects of the service. Financial difficulty, lack of counseling on fertility needs, lack of individual centered services and residual leaks were commonly reported challenges. Conclusion: Effective reintegration services should meet women's needs to the level of their anticipation. Challenges inherent in post repair reintegration require appropriate measures to mitigate dependency, loneliness and the recurrence of fistula.

\section{Background}

Linking prevention and curative strategies with rehabilitation and social reintegration programs is recognized as essential to tackling fistula holistically (1). Social re-integration is not only about reunification, but also finding alternative care if reunification is impossible (2) Physical limitations and other residual problems often hinder women's ability to work (3).Reintegration uses resources to make people capable of leading their daily life. For the reintegration, establishing rehabilitation centers, provision of literacy classes and skills training is important step to restore the women's productivity (4). It consists of individual centered interventions, by helping them identify their need and support in acquisition of the abilities and resources they need to succeed. It encompass economic, psychological, and social aspects (5). Successful surgical repair and reintegration practice enables women to resume household activities and social functioning (1). There are reports showing women's post repair quality of life has improved, and some treated women reported that they obtained clothing, soap, and transportation cost to return home on discharge (1). Despite findings showing that successful fistula repair can contribute to positive outcomes for the women and their families(6), and that reintegration has improved women's quality of life, nothing was said about the women's perspective on reintegration service and their challenges. Therefore the aim of this study was to explore women's perspectives on reintegration service and its challenges in Ethiopia. 


\section{Methods}

Qualitative study design was used. Interviews were conducted with 12 women with repaired fistula during January-February 13,2018 . The women were enrolled in the interview regardless of their repair outcome. The study purposively picked the initial participant and asked for referrals from the initial participants to find additional participants, until data saturation was reached. Women were interviewed after a minimum of one year following surgical correction. Open code version 4.03 and thematic analysis was used to analyze the data.

Semi-structured and open ended interview guides were used to explore women's views on reintegration service and identify its constraints. The tool consisted of points 1) Marital and obstetric fistula related data, 2). Women's perspectives on reintegration (what is reintegration for you? what services do you expect during reintegration?) 3) Challenges experienced by these women after repair to reintegrate into the community. (What specifically challenged you to start life again? What resources have you obtained? What constraints did you face during the service?')

Two trained female nurses who have experience of qualitative data collection were employed for data collection. Prior to interview, informed consent was obtained from each woman for both participation and audio recording.

The audio-taped, qualitative data were transcribed verbatim and translated from Amharic to English. Two independent translators ascertained the quality of translation. Transcripts were read thoroughly and meaning units were extracted and condensed without losing quality and meaning. Codes were assigned to condensed data and grouped to themed categories. Finally thematic analysis was used to interpret the data.

\section{Results}

Twelve women after fistula repair were interviewed at different settings; their median age at interview and at development of the fistula was 27 (range 24-45) years and 18 years respectively. They had lived with the condition for 3 months to13 years. Six had at least one or more living children. At the time of interview eight were divorced. They were either living alone, with their child or with their close family member (mostly mother). Repair sessions ranged from 1 to 5 surgeries with an average period of 6.25 years after treatment. After repair, five of them reported that they could control leaks completely and 6 claimed either accidental leaks when laughing or that they had difficulty in controlling or walking longer distances, standing for longer periods, doing laborious activities and bearing/carrying heavy things. One reported that she was incontinent at all times (Table 1). 
Table 1

Distribution of respondents based on their age and repair outcome; Ethiopia, 2018.

\begin{tabular}{|c|c|c|c|c|c|c|}
\hline Informant & $\begin{array}{l}\text { Age at } \\
\text { interview }\end{array}$ & $\begin{array}{l}\text { Marital } \\
\text { status }\end{array}$ & $\begin{array}{l}\text { Age at OF } \\
\text { occurrence }\end{array}$ & $\begin{array}{l}\text { Number of } \\
\text { surgeries }\end{array}$ & $\begin{array}{l}\text { Years after } \\
\text { treatment }\end{array}$ & $\begin{array}{l}\text { Continence } \\
\text { status }\end{array}$ \\
\hline 1 & 26 & Divorced & 18 & 5 & 7 & SUI \\
\hline 2 & 30 & separated & 19 & 1 & 11 & $\begin{array}{l}\text { Fully } \\
\text { continent }\end{array}$ \\
\hline 3 & 38 & Divorced & 15 & 4 & 5 & $\begin{array}{l}\text { Urinary } \\
\text { incontinent }\end{array}$ \\
\hline 4 & 33 & Divorced & 14 & 3 & 6 & SUI \\
\hline 5 & 27 & Divorced & 25 & 1 & 2 & $\begin{array}{l}\text { Fully } \\
\text { continent }\end{array}$ \\
\hline 6 & 26 & Divorced & 13 & 2 & 7 & SUI \\
\hline 7 & 27 & Married & 18 & 2 & 6 & $\begin{array}{l}\text { Fully } \\
\text { continent }\end{array}$ \\
\hline 8 & 24 & Divorced & 21 & 2 & 3 & SUI \\
\hline 9 & 26 & married & 10 & 2 & 5 & SUI \\
\hline 10 & 30 & Divorced & 28 & 1 & 2 & $\begin{array}{l}\text { Fully } \\
\text { Continent }\end{array}$ \\
\hline 11 & 45 & Divorced & 14 & 2 & 20 & SUI \\
\hline 12 & 25 & Separated & 23 & 1 & 2 & $\begin{array}{l}\text { Fully } \\
\text { Continent }\end{array}$ \\
\hline
\end{tabular}

The meaning they attached to reintegration service varied among those cured and those with unsuccessful repairs. For fully continent women, reintegration is all about support in becoming productive and leading independent life. For women with unsuccessful repair it is about healing from fistula without residual leaks and becoming as normal as their pre fistula period.

Surgical correction, resource support and restoration of social health were found to be the most important aspects of the service. Financial difficulty, lack of counseling on fertility needs, lack of individual centered services and residual leaks were commonly reported challenges.

Getting treatment and being productive

Reintegration service was stipulated as getting treatment and as the opportunity to be linked with income generation services. 
.....if government had not given attention to treat us (women with fistula) and not given the opportunity to work in the craft center, I might sit alongside for begging, because I don't have any support. I lost my marriage, my mother has died....(3 years back treated woman)

They also talked about the service in terms of working in group, as they are doing in the craft center.

"...if we get sustainable and additional financial support we will continue our life making the hand crafts ...what is more than this?" (Women previously working in the craft center)

"....it is like the chance we get now, when fistula women work together to generate income...really I am pleased to thank the government for concerning itself with fistula patients and supported them to get treated for free....then training them to work in groups to be productive.......this is more than enough.." (Women working in craft center)....

\section{Resource support}

They talked about it as enabling repaired women to help themselves through providing material, financial support and accommodation. Some focused on the direct provision of resources and the link to incomegenerating opportunities.

"...it is giving space to live in and some initial money for a woman to start a small business and help her lead her life.....unless her life will be worsened"(divorced, working in petty trade)

“.... build ability to fulfill our (women's) need of life through providing kebeles' house, training and arranging free treatment for our health problems....(woman living with her three children)

Counseling and access to fertility service

Beside the resource support they would love to have advice on how to use the resources to be productive and to have easy access to fertility related services until they fully recover.

.... providing sufficient resource to recuperate and advising on how to use/manage the money...

.....I am thankful for all that I get...sometimes we need health worker advice and support when we face challenges with things related to " werabeba"(menstruation) and pregnancy...I may discuss it with my friend but l'm afraid and feel shameful to disclose such issues to somebody (non health professional) to get help.

Providing individual woman centered support

...here our (fistula women's) effort and training is different but we earn an equal monthly salary, it is good if we can get a place to work independently......helping a woman to return to her normal life and giving resource support with advice...(woman living with her sister). 
"I have family and my husband is supportive. I want to have financial help until I fully recover and am able to work. I also need free health support and advice on future childbearing..." (Woman returned home)

Establishing/Restoring association

Respondents who lived with fistula for longer period before repair related reintegration as a means for reestablishing association with their community.

......establishing a fistula women's association to help themselves and each other...you see I was afraid to sit in the same area with other people, and if happens I will tighten my thigh sin an attempt to control the leak, but now I can sit without obsession. (separated, Woman with successful repair)

".... Living with the community without shame, associating with neighbors, rearing children as every non fistula woman does..."(26 year woman, living with her husband )

For those with unsuccessful repair reintegration is mainly related with obtaining repair treatment for their fistula problem to return to their pre-fistula status.

"...treating and curing is all about......if you are healthy you can do what you like to do...at least I can work to feed myself..." (38 yrs woman with unsuccessful repair)

Challenges experienced

After repair the women experienced different resource problems and health related challenges during their rehabilitation period. These were categorized as resource scarcity, residual incontinence and physical limitations, absence of free health service after repair, and fear of fistula relapse.

Resource scarcity

Some women got training making different hand crafts such as weaving, making baskets, and making colorful designs on cloths. Then they will be placed into the craft center to work on the field of their training. They explained that they have no extra source of support and the financial income they get monthly was not sufficient to cover the cost of daily living.

".... monthly I get 700 birr [nearly \$26], it is too small to feed my children and to pay my house rental fee. You know the market situation and I do not have another source of income. How could I lead my life with this... "(27 year women, living with two children)

Some also want to work independently if they get strong support and space, so that they can manage the maintenance and replacement of materials in a timely way and work at all times to change their lives.

"...I work on weaving, but the machine is only for four. We (those trained on weaving) are many. For the time being we can work turn by turn, but this will not make our production quicker as well our income. If I 
got strong support, I could work on my own and be more productive than this..." (26 year woman working in craft center)

Some of the women sold received items) to overcome encountered financial difficulty.

I have given mobile telephone when I come here I have to buy our food and children's issues, exercise book....

Residual incontinence and physical limitations

Although greater number of women reported repair was successful for, those who remained with residual leaks and unsuccessful repairs were double-challenged by their condition. Primarily the incontinence itself affected their working opportunities and capacities; and also their income was not significant enough to fulfill their needs in life.

"....I faced problems in many things. Though they [the people] are good hearted I refrain to sit on seats because it will get wet soon. I cannot work on household activities, I will assist them by collecting "kubet"[dried cow dung used as fuel source] and weeding it is also tiresome." (38 yrs woman with an unsuccessful repair, living with relatives)

Some of the interviewed women complained of different health problems such as dizziness, abdominal discomfort, amenorrhea, back pain, getting tired easily (lack of energy), intermittent sensation of body warmth attributing to fistula, or to number of surgical sessions they undergone.

"Previously, I was ashamed to sit with people. Because while I stand the gas (flatus) and the urine flow simultaneously. But now I can control the urine and the gas rarely occurs on activity. I can associate with people and visit friends. My main problem now is the abdominal distention resulting from the disappearance of "blood" (Menses)." (26 yrs woman)

"I am happy for my recovery but I do feel joint pain at all times in my lower extremities, I feel it happened due to repeated operation, I didn't have such problem before.(33 yrs woman, undergone three repair sessions).

"My 'period' (menstruation) is worrying me, last time it came at the seventh month. I have sometimes distension and back pain with minor activity or walking; I am worried about what is going inside..." (30yrs woman, 2 years after repair)

Lack of free health service after repair

The women obtained fistula related treatments for free. But after they were repaired they were treated as everyone who is productive and are required to pay for health services. Since they were disconnected from their productive life before and during the treatment periods, and the support they obtained was not adequate for leading a life and covering health service costs, they requested health service access for themselves and their family for free or at least at a subsidized cost. 
I did not pay for the treatment of my problem in the hospital, even they [the hospital] covered my transportation fee, but now to go to the health center for my illnesses I am required to pay, where can I get that money? I am happy if government can do similar here

I enquire people there considers my situation I cannot work and earn income as apparently healthy people and the small birr I got is just for food. Is that impossible to make as before? I request government assistance at least for my child

Fear of fistula recurrence

Given their interest in having children, nearly all the women were afraid that they were at a higher risk of developing fistula again resulting from sexual activity, child birth, or doing farm activities and carrying weighty things. Two of the participants were ready to bear the risk of fistula recurrence if happened rather than being childless. The rest had avoided sexual activity or remarriage and preferred to live away from their village, doing less demanding work.

“.... I fear its (fistula) occurrence, but I worry about my husband's status (divorce is not allowed in priests) and also I want to have another child ... I became pregnant a year back but it [the pregnancy] was not successful and failed at the 3rd month. Now I am awaiting 'his' (God's) hand....." (Woman living with her husband, 6yrs after repair)

..I want to have baby/child; I was advised that I could be pregnant after two years but I could not decide to have sexual relations, I'm frightened of the previous incident..." (Divorced woman, 5yrs after repair)...

And some developed a negative attitude towards men and spoke about their decision not to have a partner for their lifetime.

"...The 'disease' has changed my feelings about sexual relations; thanks to God I already have two children. I do not have a reason to need a man ever again..." (Divorced woman, 6yrs after repair)

"After my repair has failed, I did not go home, the problem has put all my life in hell. My life was between the alive and the dead. I do not want to think about re-marriage. Now I have to take care of myself....." (Divorced woman, 2yrs after repair)

\section{Discussion}

These qualitative interviews gave an insight into women's perspectives on the reintegration service in the study area. The meanings women attached to the service were consistent with services that most of them have obtained, such as: getting repaired, skills training, obtaining financial support, and working with women in similar scenarios to generate income. Women's reintegration concern among those whose fistulae were successfully repaired and those whose weren't was different. For those with persistent leaks their main issue was about physical repair. The success of surgery was the key component of reintegration that hastens complete recovery and found to be the priority need of patients with fistula. Similar to our study findings, different studies in Africa found that most repaired women regained 
continence, and successful fistula closure was the most important step in their reintegration $(3,7-9)$. Although some complained about urine spills with strenuous activity or coughing, many had improved continence and physical health that gave hope for returning to their pre-fistula life. Other studies also showed continence as the positive precondition for social reintegration $(2,3,10)$.

All respondents acknowledged the availability of free fistula treatment, the stipend for transportation, housing, and food for the women and their accompanying partners at the time of their referral to treatment centers. After repair some of the women were trained on making handcrafts and received pocket money, including transportation costs to return home. Some were organized into groups to work in the established craft center. If a woman works in the craft center she is paid 700.00 ETB (26 USD) per month. And with this minimal amount of money they found difficulty to lead life. However, if they produce more materials they reported that they would have additional payment (bonus). But, the lengthy period required to substitute supplies or raw materials and for maintenance was found to be a challenge to their income and motivation. To overcome this challenge, women working in the craft center would like to work independently if they had another support and space to work.

Those who received other support from the training were not self-reliant after their return. Some of the women sold received items (mobile telephone apparatus) to overcome encountered financial difficulty. And to pay for house rental, food, and children's school affairs. Some of them felt that the support did not take into account individual women's needs in terms of their reintegration needs, even if their social backgrounds may be similar. The women's service need depended on the extent of their acceptance back into their family and community, their fertility, and their skills in coping with challenges (1). They also felt that support was from organizations other than the government, and therefore requested 'government attention' and holistic support, including space to recuperate in their community and free health service until they fully recovered. A study in Kenya also revealed the need for government attention for holistic management of fistula (9).

Although different studies reported a high rate of successful fistula closure $(1,2,11,12)$, half of the respondents complained that they had stress or urge urinary incontinence, and one was persistently incontinent of urine. Five were fully continent, and the number of surgeries they had ranged between one and five with average period of 6.25 years after treatment. This is also consistent with studies conducted in Mali and Niger which revealed continence gain occurred within 5 years of care and with five or less surgeries (12).

The continence levels of most women improved after fistula repair, while other physical problems continued to challenge women directly or indirectly regardless of their repair outcome. Some complained of different ongoing problems attributed to their fistula condition, or to a number of surgical sessions they underwent. Similarly in Tanzania $48 \%$ of treated women complained of persistent physical problems (3). This is supported by a study conducted on the quality of life of women after fistula repair, and also explained that the problems are either known to be related or not related (1). 
Most women with incomplete closure continued to suffer from psychological problems, such as selfinduced isolation and lack of self-esteem. Those with successful repairs were in fear of infertility and damage to their repair (13). In addition, women's less understanding about the condition caused them to relate every physical limitation they encountered to fistula. They were worried about their reproductive health because of lack of clarity about when and what to do together with fear of relapse. That means women preferred to abstain from sex, and to avoid remarriage. Women also opt to avoid some demanding work like farming. This is similar to other studies conducted on post repair quality of life $(1,3$, 13). Those without children were uncertain whether they had the ability to bear children without developing another fistula. However, they planned to have a partner despite their fear that sexual activity would lead to another fistula. This implies that there is a need for establishing educational and counseling systems to help women and their families and communities to understand the risk conditions that lead to fistula reoccurrence (10).

Moreover, once the women returned home after their repair, they did not attend their follow-up appointments for recovery counseling if their health had improved or if they could not afford to travel. Thus, respondents would love to receive health professional advice and support at easy access as part of the reintegration service. Studies conducted in Eritrea and Kenya also magnified the need for a formal counseling service and its positive impact on improving women's knowledge of fistula, in order to improve self esteem $(9,14)$.

Those who perceived themselves healed resumed relationships, attended funerals, and visited friends. Although their feelings of loneliness were incomparable with that of pre treatment period, five of the women with unsuccessful repairs expressed that they were in fear of stigma emanating from the smell of leaked urine and they were struggling to establish interpersonal relationships. They expected the reintegration service would offer them another solution as reintegration is about providing alternative care (2). This study found that strengthening interpersonal relationships was the most important part of reintegration next to physical repair. Therefore, rehabilitation and connecting women to their community is vital $(3,9,15)$. Follow-up services could create an opportunity for counseling, identifying individual woman`s needs, and link them to income-generating activities

\section{Limitations}

This research was exploratory and the findings need to be validated through larger-scale studies in all regions of Ethiopia. Most participants received treatment from the same fistula repair center where the planning of post repair services might be similar.

\section{Conclusion}

The meaning attached to reintegration slightly differs between those women who regained continence and those with unsuccessful repairs. Surgical correction and resource support were found to be the most important services in reintegration. Financial difficulty, a lack of counseling service for fertility, the lack of 
an individual centered service, and residual leaks were challenges identified requiring appropriate measures to mitigate dependency, loneliness and recurrence of fistula.

Effective reintegration services that meet women's needs to the level of their anticipation is equally important as physical repair and assistance on discharge to address consequences of obstetric fistula.

\section{Declarations}

\section{Ethics approval and consent to participate}

Ethical clearance was obtained from the Institutional Review Board of University of Gondar (ref number: O/V/P/RCS/05/935/2016) and permission was obtained from Chief Clinical Directorate Office of the Gondar Specialized Referral Hospital of the hospital and from the fistula center coordinating office. Prior to interview an information sheet was read to the study participants to explain the purpose of the research, procedure and associated emotional risk of talking all their difficulties. Also they were informed that participation is voluntary, they do have the right to withdraw from the study at any time. Respondents were told the attainment of confidentiality and the information they give will not be used for any purpose other than study and their name and or house number or any identifications which refer to them will not be recorded. Therefore, codes were assigned and potentially identifying details were changed. They were interviewed in separate area keeping their visual and auditory privacy. Consent was obtained from each woman for both participation and audio recording

\section{Consent for publication}

Not applicable

\section{Availability of data and materials}

The qualitative data used to support the findings of this study are available from the corresponding author upon reasonable request.

\section{Competing interests}

The authors declare that they have no competing interests!

\section{Funding}

No special funding was obtained to conduct the study!

\section{Authors' contributions}

DT conceived the study, performed data analysis and interpretation, and drafted the manuscript.

AG participated in data analysis and manuscript review. 
MY participated in the proposal review, interpreted the data and edited the manuscript.

TA assisted in analysis, critically review and proof reading of the manuscript.

All authors read and approved the final version of manuscript

\section{Acknowledgements}

The authors would like to thank the University of Gondar for its support to conduct the study. The study participants, data collectors and supervisors deserve our deep gratitude for their willingness to participate in the study. Mrs. Ginny Carter is also appreciated for her assistance in the English language editing of the final manuscript.

\section{Authors' information}

DT is a Lecturer and a Nurse Practitioner in the School of Nursing, College of Medicine and Health Sciences at University of Gondar, Ethiopia. She has a Bachelor of Science Degree in Nursing, MSc in Advanced Clinical Surgical Nursing. She is a PhD student at Institute of Public Health, College of Medicine and Health Sciences, University of Gondar, Ethiopia. AG is an Associate Professor of Reproductive Health and Public Health at the Institute of Public Health, the University of Gondar, Ethiopia. He has Master of Public Health in Reproductive Health Specialty, and PhD in Public Health. He is also the Head of Amhara National Regional State Health Bureau, Ethiopia. MY is an Associate Professor of Health Service Management and Health economics at the Institute of Public Health,College of Medicine and Health Sciences, the University of Gondar, Ethiopia. He holds a Master of Public Health in Health Service Management Specialty, and a PhD in Public Health. TA is Associate professor of mental Health at the Institute of Public Health, College of Medicine and Health Sciences, University of Gondar, Ethiopia. He holds both his Master and PhD in Public Health

\section{References}

1.

Donnelly K, Oliveras E, Yewondwossen T, Belachew M, Mengistu A. The quality of life of Ethiopian women after fistula repair: Implications on rehabilitation and social reintegration policy and programming. International Journal for Research Intervention Care. 2015;2(17):150-64.

2.

Nielsen H, Lindberg L, Nygaard U, Aytenfisu H, Johnston O, Sørensen B, et al. A community-based longterm follow up of women undergoing obstetric fistula repair in rural Ethiopia. BJOG: An International Journal of Obstetrics Gynaecology. 2009;116(9):1258-64.

3.

Pope R, Bangser M. JH. R. Restoring dignity: social reintegration after obstetric fistula repair in Ukerewe, Tanzania. Glob Public Health. 2011;6(8):859-73.

4. 
Shrestha DR. Women living with obstetric fistula and nurses' role in preventive measures http://wwwacademicjournalsorg/ijnm. 2011;3(9):150-3.

5 .

Abrams P, Ridder Dd, deVries C, Sohier Elneil, Esegbona G, Mourad S, et al. Obstetric Fistula in the developing World. ICUD (International Consultation on Urological Diseases). 2010.

6.

Yeakey M, Chipeta E, Rijken Y, Taulo F, Tsui A. Experiences with fistula repair surgery among women and families in Malawi. Glob Public Health. 2011;6(2):153-67.

7.

Mselle LT, Evjen-Olsen B, Moland KM, Polit CP, Mvungi A, Kohi TW. Hoping for a Normal Life Again": Reintegration after Fistula Repair in Rural Tanzania. J Obstet Gynaecol Can. 2012;34(10):927-38. 8.

Browning A, Fentahun W, Goh JT. The impact of surgical treatment on the mental health of women with obstetric fistula. Br J Obstet Gynaecol. 2007;114(11):1439-41.

9.

Khisa AM. An Exploratory Study of Reintegration of Women Following Obstetric Fistula Surgery in West Pokot, Kenya. SAGE open. 2015:1-8.

10.

Drew L, Wilkinson JP, Nundwe W, Moyo M, Mataya R, Mwale M, et al. Long-term outcomes for women after obstetric fistula repair in Lilongwe, Malawi: a qualitative study. BMC Pregnancy and Childbirth 2016;16(2).

11.

Kayondo M, Wasswa S, Kabakyenga J, Mukiibi N, Jude Senkungu, Stenson A, et al. Predictors and outcome of surgical repair of obstetric fistula at a regional referral hospital,Mbarara, western Uganda. http://wwwbiomedcentralcom/1471-2490/11/23. 2011;11(23).

12.

Maulet N, Keita M, Macq J. Medico-social pathways of obstetric fistula patients in Mali and Niger: an 18month cohort follow-up. Tropical Medicine International Health. 2013;18(5):524-33.

13.

Browning A, Menber B. Women with obstetric fistula in Ethiopia: a 6-month follow up after surgical treatment. Br J Obstet Gynaecol. 2008;115(12):1564-9.

14.

Johnson K, Turan M, Hailemariam L, Mengsteab E, Jena D. and, et al. The role of counseling for obstetric fistula patients: Lessons learned from Eritrea. Patient Educ Couns. 2010;80:262-5. 15.

Byamugisha J, Ayadi AE, Obore S, Mwanje H, Kakaire O, Barageine J, et al. Beyond repair - family and community reintegration after obstetric fistula surgery: study protocol. Reproductive Health. 2015(12:115). 